\title{
Mapeando o sujeito em Nietzsche: a distinção entre o Ich e o Selbst
}

\author{
António Marques*
}

\begin{abstract}
Resumo: O artigo visa a analisar o estatudo do sujeito em Nietzsche. Para tanto, investiga o dispositivo de uma auto-observação exercida pelo "eu" que consiste num mapeamento do "si mesmo"; perscruta um "recuo", em relação a Kant, no plano teórico, quanto à dissolução do sujeito da tradição metafísica; e avança a tese de que o sujeito é a articulação entre o Ich e o Selbst, de modo que a compreensão do sujeito permite jogar luz sobre a relação específica entre essas duas realidades.
\end{abstract}

Palavras-chaves: Nietzsche - sujeito - ich - selbst - corpo

A conservação de si mesmo tão-só como uma das consequências da extensão de si mesmo. E o "si mesmo" (Selbst)? (Nietzsche, F. Nachlass/ FP 1885, 2 [68], KSA, 12.92).

Friedrich Nietzsche amava as montanhas e foi nelas que encontrou Zaratustra, a sua última e definitiva máscara, mas foi a descida a zonas abissais do "interior" que fez a singularidade da sua filosofia. Tal como pode ser lido em Para a genealogia da moral (1888), essa foi uma descida a "todo o mundo interior, que originariamente era tão delgado como se estivesse apertado entre duas epidermes, desenvolveu-se e ampliou-se, ganhou profundidade, largura e altura, na proporção em que foram sendo restringidas as

\footnotetext{
* Professor da Universidade Nova de Lisboa, Lisboa, Portugal. E-mail: marquesantonio@ gmail.com.
} 
Marques, A.

descargas para fora" (GM/GM II 16, KSA 5.321-324)1 . Supondo que a intenção filosófica principal do Nietzsche da maturidade consiste na descrição daquilo a que chamaremos uma antropologia centrada na vontade de poder, um dos problemas a que se deve voltar, sempre que desejamos avaliar esse programa, é ao problema do sujeito.

Não cabe aqui sequer tentar reconstituir as inúmeras versões da leitura que o estruturalismo e pós-estruturalismo foram produzindo, sobretudo ao longo das décadas de 60 e 70 do passado século. Acrescente-se o lugar central conferido a Nietzsche em interpretações da modernidade, inspiradas nesse tipo de leitura, mas já centradas numa problemática nova, ou seja, a de uma da critica radical à época moderna. Na verdade a obra de Nietzsche foi, ao longo dos anos 80, um motivo privilegiado no âmbito das discussões sobre a modernidade e a historicidade epocal desta, associadas a diversas propostas de entender a experiência pós-moderna, muitas vezes vista como experiência de desaparecimento do humano ${ }^{2}$. $\mathrm{O}$ que será de sublinhar nesse complexo, diferenciado, e tantas vezes internamente divergente universo de leituras, é precisamente o pressuposto transversal que é com Nietzsche e a partir dele que a figura de um sujeito que sustentaria toda uma época (a modernidade, as Luzes) definitivamente se apaga. Este apaga-se como se

1 As traduções para português das obras editadas ou preparadas por Nietzsche são retiradas da edição de Obras Escolhidas de Nietzsche. Lisboa: Círculo de Leitores, 1996-97, 7v. (reed. Relógio d'Água, 1998). As traduções de fragmentos póstumos, citados no presente texto, são retiradas da edição Sujeito e Perspectivismo, selecção, introdução e notas de António Marques, Lisboa: Dom Quixote, 1989.

$2 \mathrm{Na}$ verdade não é fácil encontrar autores que tenham conseguido reconstruir com sucesso o universo de interpretações, acima referido, e que, partindo de Nietzsche, façam convergir a crítica ao sujeito moderno com a critica radical à modernidade, na perspectiva de uma superação epocal desta em direcção a uma pós-modernidade ainda sem perfil reconhecível. A nosso ver, a mais sistemática e competente reconstrução desse universo complexo continua a ser a de Juergen Habermas em Der philosophische Diskurs der Moderne: Zwölf Vorlesungen. Frankfurt a. Main: Suhrkamp, 1988. Em relação à influência determinante de Nietzsche no que é possível chamar "filosofia pós- moderna" em França, mas também com incidências no mundo anglo-saxónico, ela encontra-se bem documentada nos livros de Alan D. Schift. Nietzsche and the Question of Interpretation: Between Hermeneutics and Deconstruction. New York: Routledge, 1990 e Nietzsche’s French Legacy: A Genealogy of Poststructuralism. New York: Routledge, 1995. 
apagaria qualquer ficção que se consciencializa como tal, ainda por cima depois de perder utilidade para a vida ${ }^{3}$. Tratou-se de um debate, ele próprio, epocal e quase se diria ter sido um rápido epifenómeno de estratos mais profundos. Regressar simplesmente a ele teria praticamente o significado de uma reflexão extemporânea, mas reavaliar o significado de conceitos de "sujeito", "eu", "si próprio" ou "consciência" na filosofia de Nietzsche continua a fazer todo o sentido, sobretudo no actual quadro do debate filosófico, dominado pela problemática das relações entre linguagem e mente. No que se segue gostaria que ficasse suficientemente demonstrado, primeiro, que, existe em Nietzsche um dispositivo extremamente sofisticado de auto-observação ou, se quisermos, de auto-análise, o exercido pelo "eu" (Ich) que consiste naquilo a que chamo mapeamento (termo que tomo emprestado da neurociência e da psicologia cognitiva") sobre o "si mesmo" (Selbst), sendo esse dispositivo que permite a Nietzsche colocar a hipótese de um princípio de unidade antropológico por ele designado por vontade de poder. Em segundo lugar, argumentarei que Nietzsche "recua",

3 Não será incorrecto afirmar que, em geral, a imagem estruturalista e pós-estruturalista do sujeito nietzschiano é a seguinte: o sujeito nada é acima e/ou abaixo das várias perspectivas e interpretações - os complexos de crença, desejo, acção, percepção e pensamento. Defendemos precisamente que esta imagem de sujeito como "efeito" é em parte verdadeira, mas não faz justiça às funções e estatuto do "eu" que não pode ser visto como mera consequência ilusória da dinâmica interior de um "si mesmo" (Selbst), o qual, por definição, não pensa reflectidamente.

4 Um neurocientista como António Damásio refere-se ao mapeamento não consciente que o cérebro realiza como uma função de homeostase, isto é a "manutenção do estado fisiológico dos tecidos no interior de um organismo vivo, dentro dos parâmetros homeostáticos ideais, é a origem mais profunda do valor e da valorização biológicos" (DAMÁSIO, A. O Livro da Consciência, Lisboa: Temas e Debates, 2010, p. 71). O cérebro humano, a exemplo dos de outros animais superiores, realiza essa função através da representação de estados internos sob a forma de mapas e, em particular, nos cérebros capazes de gerar linguagens, as diferentes regiões mapeadas podem receber múltiplas e diferentes etiquetas. No ser humano essa designação passa por atribuições de nomes como prazer, bem-estar, desconforto, dor, etc. Diria que, no caso de Nietzsche, estamos perante um mapeamento de segunda ordem, consciente e linguístico. A meu ver a exploração nietzschiana do "interior" corresponde a um autêntico mapeamento da diversidade das regiões/afecções que se cruzam, quer antagonicamente, quer em solidariamente no $\mathrm{eu}$. Retomarei esta ideia mais à frente. 
Marques, A.

relativamente ao que Kant tinha realizado, no plano teórico, quanto à dissolução do sujeito da tradição metafísica. O termo "recuo" não possui aqui um significado negativo, apenas pretende recolocar a filosofia de Nietzsche relativamente ao sujeito num lugar mais correcto do que aquele que vulgarmente lhe é atribuído pelo pós-estruturalismo e seus derivados. Por último quero defender a ideia que o sujeito em Nietzsche resulta de uma articulação entre o Ich e o Selbst e que compreender aquele conceito equivale a compreender a relação específica entre essas duas realidades. A analogia que fará aqui sentido introduzir é a da relação entre a mão e o corpo: pertencendo ao corpo, a mão é, por um lado, instrumento de funções altamente diversificadas e, por outro lado, não é o corpo. Este comanda, mas sem a mão não poderia apreender objectos, exprimir-se por gestos, etc. Antecipando um pouco, defendo que uma leitura adequada dos textos relevantes de Nietzsche conduz à compreensão do Ich como um instrumento reflexivo do Selbst. A sua natureza instrumental não diminui o papel relevante que desempenha na descoberta mais significativa da antropologia nietzschiana, isto é, a determinação da "vontade de poder" como explicação última ou fundamento. A argumentação que se segue não decorre forçosamente por esta ordem.

Antes de mais, considere-se a interpretação que Nietzsche faz da concepção moderna do eu. À primeira vista, parece, de alguma forma, ambígua, sobretudo se tivermos em conta o modo como ele avalia a radicalidade do programa moderno a respeito da natureza do sujeito e do "eu". Um texto fundamental é o § 54 do Para além do bem e do mal que vale a pena transcrever na íntegra:

Que fez então, no fundo, toda a filosofia moderna? Desde Descartes e, na verdade, mais por oposição a ele, do que seguindo o seu exemplo -, todos os filósofos atentam contra o conceito de alma, sob a aparência de uma crítica dos conceitos de sujeito e predicado, quer dizer, atentam contra o pressuposto fundamental da doutrina cristã, A filosofia moderna, como o cepticismo em matéria de conhecimento, é, velada 
ou abertamente, anticristã; ainda que, digamo-lo para ouvidos mais subtis, não seja de forma alguma, anti-religiosa. Outrora, acreditava-se na alma, tal como se acreditava na gramática e no sujeito gramatical; dizia-se que 'eu' é a condição, 'penso' é o predicado, o condicionado - que pensar é uma actividade para a qual um sujeito deve ser pensado como causa. Procura-se agora saber, com uma tenacidade e uma astúcia dignas de admiração, se não será possível sair desta rede e se não será talvez o contrário que é verdadeiro: 'penso' a condição e 'eu' o condicionado; o 'eu' portanto, uma síntese que só se efectua através do pensar. No fundo, Kant quis demonstrar que o sujeito não poderia ser demonstrado através do sujeito - e o objecto também não. A possibilidade de uma existência ilusória do sujeito, portanto da 'alma', pode não ter sido estranha à sua maneira de pensar, pensamento este que já uma vez aparecera na terra, com um poder inaudito, na filosofia dos vedantas (JGB/BM 54, KSA 5.73).

Justifica-se que demoremos um pouco neste notável texto. Referi uma aparente ambiguidade nele existente no que respeita à adesão que o próprio Nietzsche revela face à radicalidade que é reconhecida à crítica ao "eu" metafísico por parte da filosofia moderna. Por um lado, o representante maior dessa forma moderna de pensar, Kant, terá revelado a "existência ilusória" desse "eu" e foi ainda no quadro desse programa de dissolução da metafísica do sujeito que se inverteu a antiga relação que colocava o "eu" como condição e o pensamento como condicionado. Para Nietzsche, numa observação que será, mais perto de nós, retomada por Wittgenstein $^{5}$, a metafísica assenta fundamentalmente numa construção gramatical, que basta inverter para repor a boa perspectiva sobre essa relação. E essa inversão foi sem dúvida levada a cabo pelo modo de pensar moderno. Por outro lado, Nietzsche observa que esta filosofia ainda não se apresenta suficientemente anti-religiosa.

5 Ver por ex. o §37 das Investigações Filosóficas: "A essência exprime-se na gramática". 
Marques, A.

Não somos esclarecidos acerca dessa limitação, só compreensível para "ouvidos mais subtis", mas é possível que ele esteja, neste ponto, a sugerir a persistência na filosofia de Kant de uma forma de religião da razão prática, afinal um Ersatz da tradição religiosa. De qualquer forma a crítica ao 'eu' metafísico é aqui descrita e avaliada na ordem teórica e, nessa ordem, a radicalidade dos filósofos modernos é evidenciada por Nietzsche, sem qualquer hesitação.

Interessa sublinhar outro elemento interpretativo do texto, isto é, a característica cética atribuída à filosofia moderna, a qual terá mesmo desenvolvido essa qualidade contra a corrente cartesiana. Descontando o exagero e uma certa generalização nesta qualificação, sobretudo se tivermos em conta a referência explícita a Kant, que mesmo no plano teórico se assume como alternativa ao cepticismo, convém ler nas entrelinhas do texto nietzschiano ${ }^{6}$. Que significado atribuir, na narrativa que Nietzsche constrói acerca da modernidade europeia, ao conceito de cepticismo, tal como é aqui utilizado? A resposta não é óbvia, mas em nossa opinião, não deveremos separar a utilização, no presente contexto, do termo "ceticismo" de dois aspectos entre si associados como duas faces de uma moeda: de um lado a crítica ao "eu" metafísico como "existência ilusória", do outro a inexistência nessa mesma crítica da determinação de um elemento original ou princípio que não deixe a filosofia paralisada precisamente na ilusão desse "eu". A radicalidade céptica da critica moderna ao "eu" não será evidentemente partilhada por Nietzsche, apesar da indisfarçável admiração pela "tenacidade e uma astúcia dignas de admiração" com que se refere à inversão anti-metafísica de natureza "gramatical" operada pelo pensamento moderno.

6 A relação de Kant com o cepticismo antigo tem sido ultimamente reavaliada, no sentido da valorização do papel que, em particular o de Pírron, teve na evolução da filosofia crítica e da estruturação das antinomias da Dialéctica Transcendental. Cf. por exemplo, Michael N. Forster, que defende que "na filosofia crítica, Kant encontra-se de facto bastante ocupado com problemas de equipolência pirrónica que afectam a metafísica supra-sensível de uma forma que não apenas inclui, mas também se estende para além das quatro Antinomias canónicas" (Kant and Skepticism. Princeton: Princeton UP, 2008, p. 20). 
Afinal a "existência ilusória" do eu é um resultado extraordinário e admirável dessa astúcia moderna, mas ficar preso na contemplação desse resultado representa ainda um tipo de radicalismo que não convém à posição anti-céptica, anti-pessimista e essencialmente anti-niilista que é verdadeiramente a de Nietzsche. Por outro lado, a filosofia moderna processa uma inversão gramatical perfeitamente inultrapassável, ao determinar o "eu" como consequência do "pensar", ou melhor das forças que, no pensar, geram aquele. É no quadro desta aparente contradição que, a nosso ver, se joga a solução nietzschiana para o problema do sujeito, na dupla ordem do "eu" e do "si próprio". Antes de explorar a dicotomia "eu"/"si mesmo" assumida explicitamente por Nietzsche, será adequado reflectir um pouco na argumentação de Kant, até para colocar numa perspectiva mais nítida a sua critica ao sujeito e ao 'eu' da tradição metafísica.

É na parte da Critica da Razão Pura (1781) dedicada aos raciocínios dialécticos da razão pura relativos ao "eu", designados por Kant "Paralogismos da Razão Pura", que a critica à metafísica do "eu" ou do "eu penso" é desenvolvida com maior sistematicidade. Sem pretender descrever alargadamente a argumentação kantiana, e focando-nos apenas nalguns aspectos que mais directamente interessam à interpretação de Nietzsche, retenhamos alguns momentos do texto dos "Paralogismos". A primeira e decisiva declaração de Kant é que o "eu" não é um conceito, mas uma consciência que acompanha todos os conceitos e representações. A sua função é lógica e transcendental (na medida em que é condição de possibilidade de qualquer experiência) e não possui valor ontológico. Nesse plano de operacionalidade puramente lógica, o 'eu' desempenha uma função unitária, que não lhe confere um ser próprio, uma subsistência isolada das representações. É verdade que, sem a sua presença permanente, não haveria qualquer experiência da primeira pessoa (por ex. "penso que p", "creio que p" ou "desejo que p"), mas o "eu", ele próprio, não é objecto de experiência, apesar de ser talvez bastante intuitiva a noção de que o mais facilmente conhecível é o que está mais perto de nós. Na verdade, 
Marques, A.

é um facto da nossa experiência introspectiva mais trivial que o "eu", se desdobra (dir-se-ia, naturalmente) em "eu" observador e "eu" observado. Kant não rejeita, evidentemente, esse movimento e essa possibilidade de experiência, simplesmente coloca-os no domínio da psicologia empírica, ou seja uma ciência que estuda o "eu" como conjunto de fenómenos subordinados às regras e categorias a que também é sujeito o conhecimento de quaisquer fenómenos do mundo exterior. $\mathrm{O}$ que é alvo de análise neste capítulo da primeira Critica não é, por isso, a legitimidade de uma psicologia empírica que se circunscreve ao conhecimento de si nas suas aparências fenomenais, mas a pretensão exclusivamente metafísica de que o "eu" se conheça a si mesmo, na primeira pessoa ${ }^{7}$, como um ser simples, separado de qualquer experiência possível, idêntico, enfim um sujeito, no sentido do hypokeimenon, a que é possível adjudicar predicados vários, mas destes desligado. $O$ facto é que conhecer o "eu" como sujeito separado de predicados empíricos, mas ao mesmo tempo como seu receptáculo simples, é analiticamente impossível no sentido preciso em que conhecer supõe sempre que algo apareça na intuição. Por isso o "eu" não pode observar-se a si mesmo e simultaneamente manter o seu estatuto de simplicidade ontológica. A ilusão da metafísica acerca do eu (de uma psicologia racional na terminologia de Kant) consiste em confundir o conhecimento de si, que é o mesmo que a consciência de um "eu" que acompanha as suas representações, com o pretenso conhecimento de um 'eu' que, acolhendo predicados, é separável destes.

7 Que o pretenso conhecimento acerca do "eu" se desenrole, nos "Parologismos', sempre na perspectiva da primeira pessoa é um aspecto a sublinhar, já que é precisamente este desdobramento do 'eu' em dois, um observado e outro observador, que confere especificidade ao tipo de pseudo-conhecimento que aqui está em causa. Mesmo a minha experiência de um "eu" outro, assentará sempre numa transferência para esse outro do que em mim mesmo conheço. É o que explicita Kant com a seguinte observação: "não posso ter a mínima representação de um sujeito que pensa, mediante alguma experiência exterior, mas apenas pela consciência de mim mesmo. Também objectos semelhantes não são nada mais senão a transferência desta minha consciência para outras coisas que não podem ser representadas como objectos pensantes senão nesta condição" (Critica da Razão Pura , A 347/ B 405). 
Assim se consuma a ilusão da metafísica acerca do conhecimento do "eu": pretender que é possível aplicar funções lógicas do pensamento (as categorias de substância e de identidade, por ex.) a uma entidade que é subtraída a qualquer intuição ${ }^{8}$.

A ilação fundamental a retirar é que se pretendo conhecer-me não posso deixar de usar as categorias ou conceitos mais gerais do pensamento e que esse uso requer que algo seja dado na intuição. Porém outra consequência imediata é que a critica de Kant (unicamente na ordem teórica e não moral, prática) confirma o diagnóstico que é feito no texto citado de Nietzsche, ou seja, a crítica radical ao "eu" levada a cabo pela filosofia moderna, qualificada de cética. Neste sentido, não será incorrecto afirmar que Nietzsche não adere a esse cepticismo acerca do "eu" que os modernos desenvolveram e Kant levou ao seu limite. A pergunta a que então somos conduzidos é a seguinte: qual a resposta de Nietzsche a este desaparecimento do "eu"? Pergunta que complica o problema de saber qual a verdadeira proposta que se encontra na sua filosofia acerca da natureza do sujeito. Os termos a que é possível reduzir o problema equivalem a uma quase aporia, no sentido em que se, por um lado, Nietzsche se distancia do cepticismo moderno quanto "eu" e ao sujeito, a que Kant nos "Parologismos" fechou a porta, por outro lado, desse legado moderno o próprio Nietzsche aceita sem hesitações a qualificação do "eu" como efeito e ilusão.

Alguns autores pretendem, como é o caso de Stanley Rosen, que os escritos de Nietzsche são uma resposta retórica (em particular o seu Zaratustra, com a correspondente retórica da criação e transmutação de valores) à concepção nietzschiana do ser como caos. Esta identificação supostamente sugerida por Nietzsche

8 Quando pretendo conhecer-me como "eu" que pensa, não posso evidentemente subtrair-me à condição de 'eu' existente que pensa e, por isso, à operação reflexiva em que me coloco a mim mesmo, na condição de objecto fenoménico. Uma passagem bastante esclarecedora dos "Paralogismos" é a seguinte: "a proposição: eu penso, na medida em que vai ao ponto de significar existo pensando (Ich existire denkend) não é uma função puramente lógica ...." (Crítica da Razão Pura, B 429/430). 
entre ser e caos não é, no entanto, convincente, em primeiro lugar porque não conhecemos nenhuma declaração do filósofo que apresente as forças que atravessam o corpo (individual e social) como um agregado desordenado e indistinto. Afirmar como Rosen, aliás na esteira de Heidegger", que Nietzsche "reduz a própria ciência matemática, o principal produto do Iluminismo, ao caos" significa passar por cima do minucioso mapeamento que ele leva a cabo do "interior" do sujeito ${ }^{10}$. Esta é uma constatação aceite naturalmente, quer pela actual neurociência, quer pela recente psicologia cognitiva. No primeiro caso, o já citado António Damásio sublinha que "a consciência é uma propriedade importante de organismos vivos ...." e que "uma chave para compreender organismos vivos, a partir daqueles que são constituídos de uma célula até àqueles que são constituídos por biliões de células, é a definição dos seus limites, a separação entre o que está dentro e o que está fora. A estrutura do

9 Cf. Heidegger, nas suas lições sobre Nietzsche: Nietzsche I, Guenter Neske, Pfuellingen, 1961, p. 555. O "caos" aparece no comentário de Heidegger e no contexto da sua interpretação de Nietzsche, como o último metafísico, para o qual "conhecer", no sentido no metafísica moderna, não é mais do que impor esquemas a uma realidade cática ou informe. De facto é assim que Nietzsche compreende o conhecimento gerado pela época moderna, o qual não prescinde da manipulação e da experimentação do real. Mas a sua crítica dirige-se mais profundamente à dicotomia que sustenta essa noção epocal do "conhecer": o esquema contra o caos. É essa forma de conhecimento, caracterizador da epistemologia da filosofia moderna, que Nietzsche designa de "perspectivismo": impor ao caos certas formas simplificadoras de modo a conhecê-las. Tal processo traduz, afinal, não mais do que uma perspectiva, a qual visa, em última análise, o domínio. "Todo o aparelho de conhecimento é um aparelho de abstracção e de simplificação, que não visa o conhecimento, mas o domínio sobre as coisas", esclarece Nietzsche num fragmento póstumo, entre inúmeros do mesmo tipo (Nachlass/FP 188426 [61], KSA 11.164). O perspectivismo intrínseco à epistemologia da época moderna é uma das melhores expressões de uma vontade de domínio ou, mais concretamente, de manipulação, e a realidade primordial a revelar por detrás desse processo é a vontade de poder. No entanto, será que esse reconhecimento de uma realidade última conduz a uma epistemologia alternativa? A nosso ver não conduz, e a atitude a que Nietzsche nos convida é antes a uma investigação que combina a auto-análise ou conhecimento de si com uma perspectiva de terceira pessoa com base histórico-genealógica. Daí resulta um verdadeiro mapeamento que identifique uma topologia interior de afectos primordiais. Cf. nossa Introdução a Sujeito e Perspectivismo, op. cit.

10 Cf. ROSEN, S. The Mask of Enlightenment - Nietzsche's Zarathustra. 2a. ed. New Haven and London: Yale UP, 2004, p. XVII. 
organismo está no interior de limites e a vida do organismo é definida pela manutenção de estados internos no interior dos limites. A individualidade singular depende dos limites"11.

Deste modo, aquilo a que chamei mapeamento do corpo não é de forma alguma processado sobre um magma caótico, o que confirma certamente a noção lógica de que um caos não é mapeável. Antecipando um tema que menciono mais à frente, o método proposto por Nietzsche será antes o de "seguir o fio condutor do corpo", fórmula com o seu ingrediente retórico, mas detentora do significado iniludível de uma identificação dos topoi principais da vida afectiva, no sentido mais profundo dos sentimentos morais que o homem interiorizou. Em vez do caos, o ponto de partida de Nietzsche é antes a verificação, mais do que mera hipótese, que "todos os instintos que se não libertam para o exterior viram-se para dentro: a este processo chamo a interiorização do homem" (GM/GM II 16, KSA 5. 321-4).

É agora altura de avaliarmos o instrumento reflexivo do Selbst que é o Ich e caracterizar a actividade cognitiva que Nietzsche lhe reserva. Para tanto sugerimos a utilização de dois capítulos do Assim falava Zaratustra, no Livro I, intitulados "Dos Visionários do Além-Mundo" e "Dos Desprezadores do Corpo", sem os quais não é possível compreender ao problema do sujeito na sua filosofia. Restrinjo a minha análise a alguns pontos mais significativos. Em “Dos Visionários ..." Zaratustra pugna pela criação de novos

11 DAMÁSIO, A. The Feeling of What Happens- Body and Emotion in the Making of Consciousness. New York/London: Harcourt Brace \& Company, 1999, p. 135-6. Também para alguns psicólogos cognitivos, a primitiva formação de uma auto-consciência do corpo está ligada à apreensão e limites do "si mesmo" incorporado e à directa consequência do estabelecimento de limites entre o self e o que o não é. Cf. Entre outros, o recente estudo de José Bermudez, "Bodily Awareness and Self-Consciousness" (The Oxford Handbook of the Self. Oxford: Oxford University Press, 2011). Para o problema do sujeito de que aqui se trata, é interessante a forma como este auto-conhecimento sublinha a diferença entre a consciência do corpo próprio que é dada nas chamadas percepções internas (proprioceptivas) e a percepção que é nos é dada nas percepções externas. Compare-se, por exemplo, a diferença entre a percepção que posso ter da minha perna esquerda cruzada sobre a direita (sem observar) e a de uma cicatriz na minha mão direita. 
valores e são atacados os visionários de um além-mundo contra a vida e a sua expressão mais directa e genuína, o corpo. Nesse capítulo (contrariando claramente as leituras que defendem um quase apagamento das funções do "eu" face à primazia do corpo), encontramos a seguinte passagem: "Na verdade, o Ser é sempre difícil de demonstrar e é difícil fazê-lo falar. Dizei-me vós, irmãos, não é a mais singular de todas as coisas também a mais bem comprovada? Sim, este Eu, com a contradição e a confusão do Eu, ainda é quem fala mais honestamente do seu ser, este Eu que cria, quer e avalia, Eu que é a medida e o valor das coisas. E este ser, de todos o mais honesto, que é o Eu, fala do corpo e até quer o corpo, mesmo quando imagina, devaneia e esvoaça com as asas partidas" (Za/ZA I, Dos Visionários do além mundo, KSA 4.35-8) ${ }^{12}$. Surpreenderá esta passagem aqueles que, apoiados sem dúvida em diversos textos de Nietzsche, retiram ao "eu" qualquer função relevante na constituição do sujeito, preferencialmente identificado com o corpo (Leib). Aquele é ainda quem, apesar da "confusão e contradição", mais honestamente fala do ser. Também deve ser visto como o "avaliador" e a "medida de todas as coisas". Na verdade, o seu papel mais relevante ainda não aparece completamente explícito, mas somos informados de algo que é exposto claramente no capítulo seguinte, "Dos Desprezadores do Corpo". Os autores das melhores exegeses do Zaratustra, Laurence Lampert e Stanley Rosen ${ }^{13}$, interpretam este

12 Será de ter em conta que este é um capítulo do Zaratustra que corresponde à sua metamorfose em "leão", o que significa que a sua reflexão acerca do natureza do "eu" e do "si mesmo" (correspondente ao corpo) é feita sob o signo da liberdade criativa. O 'leão' cria liberdade para uma nova criação". No capítulo seguinte, "Dos Desprezadores ...” já o discurso é sob o signo da 'criança', a outra metamorfose (para além da primeira, a do 'camelo'). Sabe-se como a criança representa um novo começo, uma inocência a partir donde tudo pode começar de novo, enfim a terra fértil onde novos valores são gerados. Esta secção difícil, mas decisiva do Zaratustra, não é compreensível sem ter em conta essa metamorfose: o 'eu' que "cria, quer e avalia" ainda não se auto-reconhece como instrumento do corpo, ainda não descobriu a supremacia do 'si mesmo', equivalente ao corpo.

13 LAMPERT, L. Nietzsche's Teaching-An Interpretation of Thus Spoke Zarathustra”. Yale: Yale University Press, 1986; ROSEN, S. The Mask of Enligthenment, op. cit. 
último capítulo como introduzindo uma descontinuidade significativa em relação ao capítulo anterior. Sobretudo Rosen chama a atenção para uma mudança crítica na forma de compreender a primazia do $\mathrm{eu}^{14}$. A partir do momento em que a criança fala aos que desprezam o corpo e afirma que ela é "corpo e alma" abre-se o caminho para uma absoluta primazia do corpo e à correspondente dissolução do ego: "Deve ser lembrado que na doutrina amadurecida de Nietzsche não existe "eu". O "eu" é uma combinação ilusória de pontos de consciência em contínua dissolução, que são, eles próprios, afectos psicológicos ou, na sua base, momentos de vontade de poder"15. Por outras palavras, na interpretação de Rosen, Nietzsche será um céptico em relação à existência de um 'eu' e certamente de um sujeito em que o 'eu' represente um princípio de unidade. Neste sentido a filosofia de Nietzsche repetirá a inspiração céptica da filosofia moderna a este respeito, em particular aquela linha de pensamento representada por Kant.

Já atrás notei que tal interpretação não é a correcta e que Nietzsche não coincide com essa crítica radical, argumentada nos "Parologismos" da primeira Critica. Deveremos conceder que a natureza perspectivista do 'eu' é evidentemente indesmentível. Nietzsche define-o assim mesmo, por diversas vezes, mas o seu estatuto não deve reduzir-se a uma inexistência, tal como qualquer produção perspectivista não é um nada. Basta pensar que uma produção perspectivista possui sentido, enquanto o nada do niilista consiste precisamente na radical falta de sentido. A unidade aparente do 'eu' corresponde na verdade a esse estatuto perspectivista, assim como em Kant o seu estatuto, independente de toda e qualquer representação empírica, lhe retirava qualquer realidade ou qualidade ontológica. Apesar de todas as diferenças (em Kant é o 'eu' que assegura a unidade das representações, enquanto essa é uma função

14 Cf. S. ROSEN, id., p. 84 e segs.

15 Ibidem, p. 82. 
que não se encontra em Nietzsche), ambas as filosofias reservam funções ao Ich que não são compatíveis com o seu desaparecimento, a sua transformação em "nada", embora seja um facto que também ambos rejeitam a identificação de um "eu" com um sujeito metafísico e hipostasiado. Considerando apenas os fragmentos ao longo do Nachlass, são inúmeras as afirmações, hipóteses, sugestões acerca da natureza do 'eu' que confirma o que acabo de referir ${ }^{16}$.

Interpretações como a de Stanley Rosen (a qual, como já referimos, vai bastante na linha do pós-estruturalismo, ainda que seja um autor nos antípodas daquela família de filosofias), para quem o 'eu' não existe no pensamento maduro de Nietzsche, são contrariadas em especial pelos capítulos do Zaratustra mencionados. $\mathrm{O}$ facto do Ich não ser o sujeito, o qual Nietzsche identifica antes com a realidade que é o corpo, a que também chama "grande razão" e ser considerado antes como um instrumento do Selbst que usa o Ich como seu instrumento, não lhe retira importância. Será esclarecedora a leitura de seguinte excerto do já citado capítulo do $Z a$ ratustra, acerca dos que menosprezam o corpo. Depois de colocar o seu discurso sob a tutela do espírito da criança, que está aberta à génese de novas concepções, mas que ingenuamente ainda acredita que o sujeito é uma composição de alma e de corpo, Zaratustra comunica-nos o seguinte:

O corpo é uma grande razão, uma multiplicidade com um só sentido, uma guerra e uma paz, um rebanho e um pastor. Instrumento do teu corpo é também a tua pequena razão, meu irmão, a que tu chamas "espírito", um pequeno instrumento e um brinquedo da tua grande razão.

16 Cf. o seguinte fragmento do Nachlass: "Se o nosso 'eu' é o único ser segundo o qual nós fazemos ser tudo e compreendemos tudo - muito bem ! - torna-se então pertinente a dúvida sobre se não se tratará de uma ilusão de perspectiva: a da unidade aparente em que, como numa linha do horizonte, tudo converge e se encadeia. Seguindo o fio condutor do corpo, revela-se uma extraordinária multiplicidade ..." (Nachlass/FP 1885, 2 [91], KSA 12.106) [grifo nosso]. 
"Eu", dizes tu e orgulhas-te dessa palavra. Mas maior é aquilo em que não queres acreditar: o teu corpo e a sua grande razão, que não diz "Eu", mas faz "Eu". Aquilo que a mente sente, aquilo que o espírito conhece, isso nunca tem um fim em si mesmo o seu fim. Mas a mente e o espírito gostariam de convencer-te de que são o fim de todas as coisas: pois são vaidosos a esse ponto. Instrumentos e brinquedos é o que são a mente e o espírito: atrás deles ainda se encontra o Si Mesmo (das Selbst). O Si Mesmo está sempre à escuta e à procura: compara, submete, conquista, destrói. Ele reina e é igualmente o soberano do Eu. Por detrás dos teus pensamentos e sentimentos, meu irmão, encontra-se um poderoso amo, um sábio desconhecido, que se chama Si Mesmo. É no teu corpo que ele reside, ele é o teu corpo (....) (Za/ZA I, Dos Desprezadores do Corpo, KSA 4.39-31) .

O estatuto do sujeito fica melhor esclarecido nesta passagem. Este não existe como um "eu" destacado do corpo e é este que comanda aquele. No entanto, é de sublinhar que esse comando não significa que o corpo pense ou reflicta, já que se encontra "atrás do pensamento". A melhor designação que Nietzsche encontra para essa entidade soberana que não pensa, mas obriga a pensar e reflectir, é "si mesmo" (Selbst). Mais à frente, no mesmo capítulo, a relação entre o corpo, como "si mesmo", e o "eu" é ainda mais explícita. “O Si Mesmo diz ao Eu: “Agora sente dor!'. E, então, este sofre e reflecte sobre a maneira de não sofrer mais - e é precisamente para isso que ele deve pensar. O Si Mesmo diz ao Eu: "Agora, sente prazer!". Então este regozija-se e reflecte sobre a maneira de ainda se regozijar muitas vezes - e é precisamente para isso que ele deve pensar".

Percebe-se então que o instrumento que é o "eu" tem como sua função pensar e reflectir sob o comando do "si próprio". Na verdade se juntarmos a estas funções aquilo que sobre ele é ensinado pelo mesmo Zaratustra no capítulo imediatamente anterior, em que o "eu" também "cria, quer e avalia", então fica-se com uma ideia ainda mais clara acerca do seu estatuto a que chamarei 
instrumental reflexivo. Dentro desse âmbito o "eu" é também um conhecedor, aquele conhecedor que não se ocupa de si como o objecto central de análise, mas sim conhecedor em relação ao corpo como "si próprio". No livro que, talvez mais sistematicamente do que qualquer outro na obra de Nietzsche, Para a genealogia da moral, desenha um mapa das afecções primordiais do sujeito (do corpo do sujeito ou deste como si próprio) o homem é um conhecedor. Nas primeiras linhas desse livro, é-nos dito que nos desconhecemos a nós próprios, "nós que conhecemos (wir Erkennenden)". Conhecer-nos equivale, de um ponto de vista metodológico e não só, seguir o fio condutor do corpo, representa precisamente essa operação de mapeamento dos afectos que o estruturam. Nessa exploração o instrumento reflexivo encontra, como é sabido, um fundamento inultrapassável desse mapa que é a vontade de poder.

Sendo assim, o problema que motivou este texto, o estatuto do sujeito em Nietzsche, começará por ser esclarecido com duas respostas negativas. O sujeito não é o "eu" porque este é apenas instrumento determinado pelo corpo enquanto "si próprio", mas também não é o corpo porque este também precisa desse "eu" que deve pensar e reflectir para si. Resulta igualmente como relevante da presente análise a inexistência na filosofia de Nietzsche de qualquer elemento cético sobre o estatuto do sujeito.

\footnotetext{
Abstract: This paper aims to analyse the statute of the subject in Nietzsche. For this purpose, it investigates the device of a self-observation provided by the "I", which consists in a mapping of the "self in itself"; on a theoretical level, it explores a "retreat" in relation to Kant, concerning the dissolution of the subject of the metaphysical tradition; and anticipates the point that the subject is an articulation between the Ich and the Selbst, in such a way that the understanding of the subject allows to enlighten the specific connection between these two realities.

Keywords: Nietzsche - subject $-i c h-$ selbst - body
} 


\section{referências bibliográficas}

BERMUDEZ, J. "Bodily Awareness and Self-Consciousness". In: The Oxford Handbook of the Self, Oxford: Oxford University Press, 2011.

DAMÁSIO, A. The Feeling of What Happens- Body and Emotion in the Making of Consciousness. New York/London: Harcourt Brace \& Company, 1999. . O Livro da Consciência. Lisboa: Temas e Debates, 2010.

FOSTER, M. Kant and Skepticism. Princeton: Princeton UP, 2008;

HABERMAS, J. Der philosophische Diskurs der Moderne. Frankfurt a. Main: Suhrkamp, 1988.

. O Discurso Filosófico da Modernidade. Lisboa: Dom Quixote, 1989.

HEIDEGGER, M. Nietzsche I. Pfuellingen: Guenter Neske, 1961.

LAMPERT, L. Nietzsche's Teaching-An Interpretation of Thus Spoke Zarathustra". Yale: Yale University Press, 1986.

MARQUES, A. Sujeito e Perspectivismo- selecção de textos de Nietzsche sobre teoria do conhecimento. Lisboa: Dom Quixote, 1989.

NIETZSCHE, F. Kritische Studien Ausgabe. Berlim: W. de Gruyter, 1975-1984, 15v. (edição G. Colli- M. Montinari).

ROSEN, S. The Mask of Enlightenment - Nietzsche's Zarathustra. 2a. ed. New Haven and London: Yale UP, 2004.

WITTGENSTEIN, L. Philosophical Investigations. Oxford: Basil Blackwell, 1953.

Artigo recebido em 10/10/2012.

Artigo aceito para publicação em 15/11/2013. 